\title{
Prevalence of Type 2 Diabetes Mellitus in Metabolic Syndrome Individuals
}

\author{
Khalid S Aljabri ${ }^{1}$, , Samia A Bokhari ${ }^{1}$, Muneera A Alshareef ${ }^{1}$, Patan M Khan ${ }^{1}$ and Bandari K Aljabri ${ }^{2}$ \\ ${ }^{1}$ Department of Endocrinology, King Fahad Armed Forces Hospital, Saudi Arabia \\ ${ }^{2}$ College of medicine, Um Al Qura University, Saudi Arabia
}

*Corresponding author: Khalid S J Aljabri, Department of Endocrinology, King Fahad Armed Forces Hospital, Jeddah, Kingdom of Saudi Arabia, Jeddah 21159, Kingdom of Saudi Arabia

Submission: 悳 September 07, 2018; Published: 眥 October 05, 2018

\begin{abstract}
Background and Objective: Metabolic syndrome (MetS) is a cluster of metabolic factors. Studies have reported on diabetes prevalence in this population. The aim of this study was to determine the prevalence of type 2 diabetes mellitus (T2DM) in MetS in Saudi population.

Methods: We analyzed 1967 participants who are equal to or older than 18 years old. All cases were from the population of the primary health at King Fahad Armed Forces Hospital. All data were collected by personal interview and based on a review of electronic medical records. Physician and nurse interviewers measured and recorded weight $(\mathrm{kg})$ and height $(\mathrm{cm})$. Metabolic risk factors were defined using the 2006 IDF criteria that define elevated triglyceride as $\geq 150 \mathrm{mg} / \mathrm{dL}$ ( $\geq 1.7 \mathrm{mmol} / \mathrm{L}$ ) and reduced HDL as $<40 \mathrm{mg} / \mathrm{dL}(<1.03 \mathrm{mmol} / \mathrm{L}$ ) for male and as $<50 \mathrm{mg} / \mathrm{dL}$ ( $<1.29 \mathrm{mmol} / \mathrm{L})$ for female. Hypertension was defined when the systolic blood pressure was $\geq 130 \mathrm{~mm} \mathrm{Hg}$ and/or diastolic blood pressure was $\geq 85 \mathrm{~mm} \mathrm{Hg}$ in addition to receiving any medication for hypertension. Abnormal glucose metabolism was con $\neg$ sidered when $\mathrm{HbA1c}(\geq 5.7)$ or when patients were known to have T2DM. Participants were defined as having T2DM according to self-report, clinical reports, use of antidiabetic agents and HbA1c ( $\geq 6.5)$. Body mass index (BMI) values classified into groups as lean (BMI $<18.5)$, normal weight (BMI $=18.5-24.9 \mathrm{~kg} / \mathrm{m} 2)$, overweight $(\mathrm{BMI}=25.0-29.9 \mathrm{~kg} / \mathrm{m} 2)$, obese $(\mathrm{BMI} \geq 30 \mathrm{~kg} /$ $\mathrm{m} 2$. The total number of cohorts were separated on basis of age values into five groups: $<30$ years, 30-39 years, $40-49$ years, $50-59$ years and $\geq 60$ years.

Main results: Of the 1967 participants with MetS analyzed, 763 (38.8\%) were male and 1204 (61.2\%) were female. Age was $54.5 \pm 12.8$ (minimum 18 years and maximum 105 years) and mean BMI 31.9 \pm 6.6 . T2DM was present in 1524 cases (77.5\%) where 607 (39.8\%) were male and 917 (60.2\%) were female with female to male ratio $1.5: 1, \mathrm{P}=0.08$. Males were no significantly older than females in MetS with T2DM patients $(56.2 \pm 12.2 \mathrm{vs}$. $48.7 \pm 13.1$ respectively, $\mathrm{p}<0.0001)$. BMI was no significantly higher in males than females with MetS with T2DM patients ( $32.0 \pm 6.8$ vs. $31.4 \pm 5.8$ respectively, $\mathrm{p}=0.1)$. MetS with T2DM prevalence is consistently increasing with increasing age until the sixth decade $(\mathrm{p}<0.0001)$. Moreover, higher prevalence is among age group $\geq 60$ years of age in males. MetS with T2DM prevalence is consistently increasing with increasing BMI category with higher prevalence than MetS without T2DM at the BMI $\geq 30 \mathrm{~kg} / \mathrm{m} 2$. Higher prevalence is among females in Mets with T2DM. Mean BMI in population of MetS with T2DM is consistently decreasing with increasing age until the sixth decade after a peak at the age 30-39 years $(\mathrm{p}<0.0001)$. Moreover, Mean BMI in population of MetS with T2DM is higher among female group with curve separated starting at the age $<30$ years. The mean of BMI among MetS is statistically significant negatively correlated with increasing with advanced age $(\mathrm{r}=-0.1, \mathrm{p}<0.0001)$.
\end{abstract}

Conclusion: The prevalence of T2DM among Saudis with MetS is relatively high. Old age and obesity can be regarded as related factors.

Keywords: Type 2 diabetes mellitus and metabolic syndrome

\section{Introduction}

Metabolic Syndrome (MetS) can be defined as a cluster of cardio-metabolic dysfunctions characterized by the increase in fasting blood sugar, abdominal circumference, hypertension (HTN), triglycerides (TG) and reduction in high-density lipoprotein cholesterol (HDL) [1]. The prevalence of MetS is increasing all over the world with different regions having individual clusters of epidemic risk factors and there is evidence of a high prevalence of MS and diabetes in Asians [2,3]. Affecting approximately 25\% of the world population, MetS accounts for $7 \%$ of overall mortality and $17 \%$ of deaths associated with cardiovascular disease (CVD). The literature emphasizes that individuals with MetS are two times more likely to die, regardless of the cause; three times more likely to have a heart attack and/or stroke; and five times more likely to develop type 2 diabetes (T2DM) [4,5].

First describing MetS in 1988, Reaven discussed several metabolic findings with this syndrome and proposed that the central characteristic is insulin resistance with an increased risk for diabetes and CVD $[5,6]$. Although the clinical application and practicality of the syndrome continue to be debated, the definition of MS was debated for a long time to produce a standardized clinical criterion [7,8]. The first official definition of MetS put forward by a working group of the World Health Organization (WHO) in 
1999, a number of different definitions have been proposed [9]. WHO describes MS as the presence of T2DM or impaired glucose tolerance with any two of the following characteristics: obesity, high levels of TG, low levels of HDL, and HTN.

Previous cross-sectional studies have indicated a high prevalence of risk factors for diabetes, including obesity, impaired glucose tolerance and MetS, among Aboriginal Canadians [10]. Recent studies have reported on diabetes incidence in this population using data from an administrative database and a hospital registry [11]. It is estimated that, in $2010,6.4 \%$ of adults would have diabetes mellitus affecting 285 million in the world and it will increase to $7.7 \%$ by 2030 , affecting 439 million adults [12]. Of special note is that there will be a $67 \%$ increase in the prevalence of diabetes in developing countries from 2010 to 2030 [12]. Sixty-one percent of newly diagnosed patients with type 2 diabetes also fit the criteria for MetS and are at a significantly higher risk of stroke or myocardial infarction in a 10-year period while patients with MetS have a five- to sevenfold increased risk of developing T2DM [6].

It is essential to initiate early detection of these chronic diseases in underdeveloped countries in Asia, such as Saudi Arabia, so that preventative action can minimize the consequences. Despite the prevalence of MetS is well known in various populations, there is no in-depth information available about the prevalence of T2DM individuals with MetS within combined subgroups of sex, BMI and age. Therefore, the aim of this study was to determine the prevalence of T2DM in Saudi population with MetS.

\section{Methods}

We analyzed 1967 participants who are equal to or older than 18 years old. All cases were from the population of the primary health at King Fahad Armed Forces Hospital. All data were collected by personal interview and based on a review of electronic medical records. Physician and nurse interviewers measured and recorded weight $(\mathrm{kg})$ and height $(\mathrm{cm})$. Metabolic risk factors were defined using the 2006 IDF criteria that define elevated triglyceride as $\geq 150 \mathrm{mg} / \mathrm{dL}(\geq 1.7 \mathrm{mmol} / \mathrm{L})$ and reduced $\mathrm{HDL}$ as $<40 \mathrm{mg} / \mathrm{dL}$ $(<1.03 \mathrm{mmol} / \mathrm{L})$ for male and as $<50 \mathrm{mg} / \mathrm{dL}(<1.29 \mathrm{mmol} / \mathrm{L})$ for female [13]. HTN was defined when the systolic blood pressure was $\geq 130 \mathrm{~mm} \mathrm{Hg}$ and/or diastolic blood pressure was $\geq 85 \mathrm{~mm} \mathrm{Hg}$ in addition to receiving any medication for hypertension. Abnormal glucose metabolism was considered when HbA1c $(\geq 5.7)$ or when patients were known to have type 2 diabetes. Participants were defined as having T2DM according to self-report, clinical reports, use of antidiabetic agents and HbA1c ( $\geq 6.5$ ) [14]. Body mass index (BMI) values classified into groups as lean (BMI <18.5), normal weight $\left(B M I=18.5-24.9 \mathrm{~kg} / \mathrm{m}^{2}\right)$, overweight $(B M I=25.0-29.9 \mathrm{~kg} /$ $\mathrm{m}^{2}$ ), obese $\left(\mathrm{BMI} \geq 30 \mathrm{~kg} / \mathrm{m}^{2}[15]\right.$. The total number of cohort were separated on basis of age values into five groups: <30 years, 30-39 years, $40-49$ years, $50-59$ years and $\geq 60$ years.

\section{Statistical Analysis}

Unpaired t-test analysis and Chi square $\left(\mathrm{X}^{2}\right)$ test (categorical data comparison) were used between variables to estimate the significance of different between groups for demographic and clinical laboratory. The independent relationship between T2DM and the odds ratio of having MetS were analyzed using Chi square $\left(\mathrm{X}^{2}\right)$. All statistical analyses were performed using SPSS Version 22.0. The difference between groups was considered significant when $\mathrm{P}<0.05$.

\section{Results}

Of the 1967 participants with MetS analyzed, 763 (38.8\%) were male and 1204 (61.2\%) were female. Age was 54.5 \pm 12.8 (minimum 18 years and maximum 105 years) and mean BMI 31.9 \pm 6.6 , Table 1. T2DM was present in 1524 cases (77.5\%) where 607 (39.8\%) were male and $917(60.2 \%)$ were female with female to male ratio 1.5:1, $\mathrm{P}=0.08$. Males were no significantly older than females in MetS with T2DM patients $(56.2 \pm 12.2$ vs. $48.7 \pm 13.1$ respectively, $\mathrm{p}<0.0001)$. BMI was no significantly higher in males than females with MetS with T2DM patients (32.0 \pm 6.8 vs. $31.4 \pm 5$.8respectively, $\mathrm{p}=0.1)$.

Table 1: Characteristics of the population with metabolic syndrome under study stratified by type 2 diabetes mellitus presence (means \pm SD or number $(\%)$ ).

\begin{tabular}{|c|c|c|c|c|c|}
\hline \multicolumn{2}{|c|}{ Parameters } & \multirow{2}{*}{$\begin{array}{c}\text { Total } \\
\text { Present }\end{array}$} & Type 2 Diabetes Mellitus & P Value \\
\cline { 3 - 6 } & & 1967 & $1524(77.5)$ & $443(22.5)$ & \\
\hline $\mathrm{n}(\%)$ & & $54.5 \pm 12.8$ & $56.2 \pm 12.2$ & $48.7 \pm 13.1$ & $<0.0001$ \\
\hline Age (years) & Male & $763(38.8)$ & $607(39.8)$ & $156(35.2)$ & 0.08 \\
\hline \multirow{2}{*}{ Gender } & Female & $1204(61.2)$ & $917(60.2)$ & $287(64.8)$ & $31.4 \pm 5.8$ \\
\hline Body mass index $\left(\mathrm{kg} / \mathrm{m}^{2}\right)$ & & $31.9 \pm 6.6$ & $32.0 \pm 6.8$ & 0.1 \\
\hline
\end{tabular}

MetS with T2DM prevalence is consistently increasing with increasing age until the sixth decade $(\mathrm{p}<0.0001)$, Figure 1. Moreover, higher prevalence is among age group $\geq 60$ years of age in males, Figure 1. MetS with T2DM prevalence is consistently increasing with increasing BMI category with higher prevalence than MetS without T2DM at the BMI $\geq 30 \mathrm{~kg} / \mathrm{m}^{2}$, Figure 2. Higher prevalence is among females in Mets with T2DM, Figure 2. Mean
BMI in population of MetS with T2DM is consistently decreasing with increasing age until the sixth decade after a peak at the age 3039 years $(\mathrm{p}<0.0001)$, Figure 3. Moreover, Mean BMI in population of MetS with T2DM is higher among female group with curve separated starting at the age $<30$ years, Figure 3 . The mean of BMI among MetS is statistically significant negatively correlated with increasing with advanced age $(r=-0.1, p<0.0001)$. 


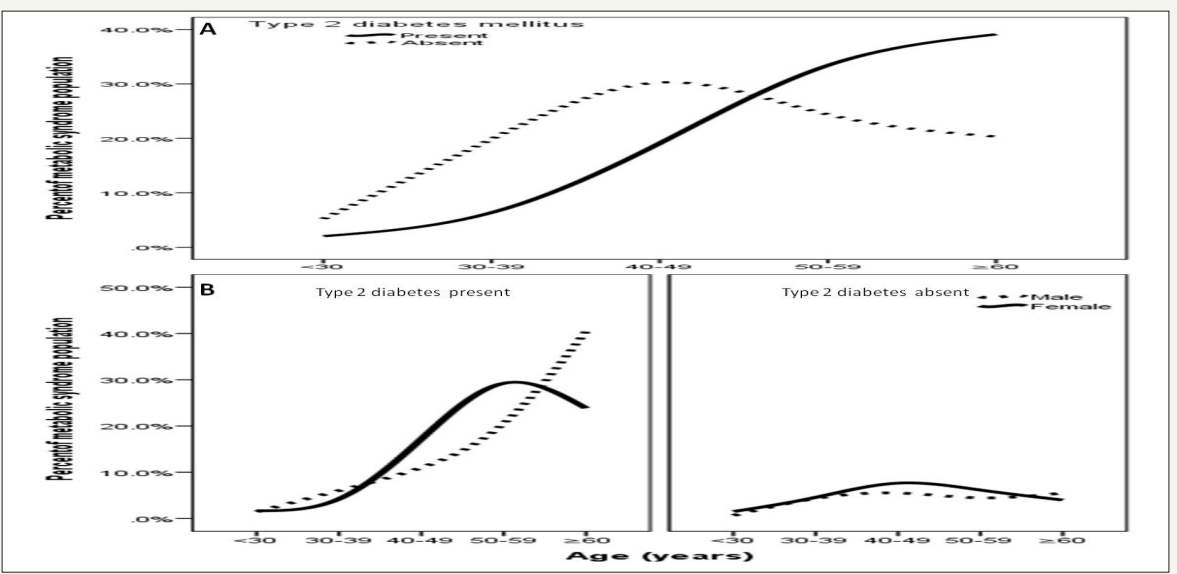

Figure 1: Percentage of metabolic syndrome across different age groups stratified to type 2 diabetes (A) and in relation to gender (B).

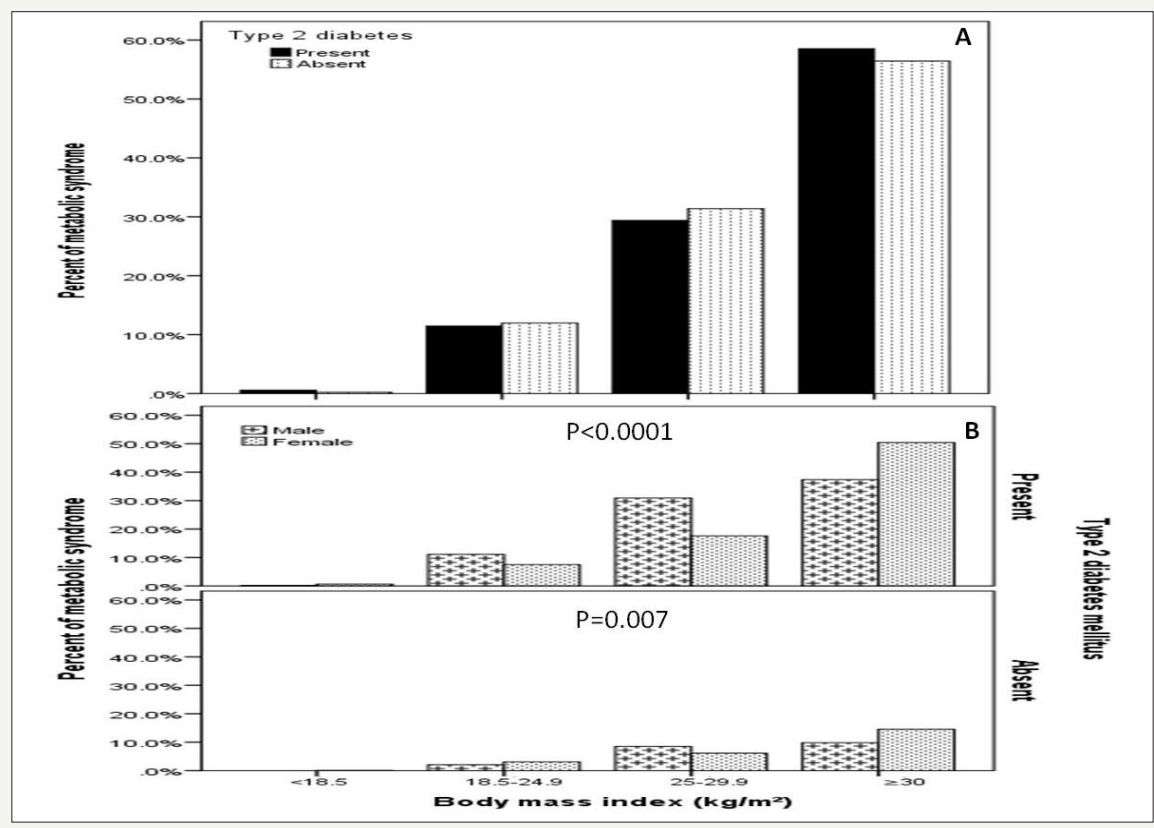

Figure 2: Percentages of metabolic syndrome in relation to presence of type 2 diabetes across different body mass index ranges (A) and in relation to gender (B).

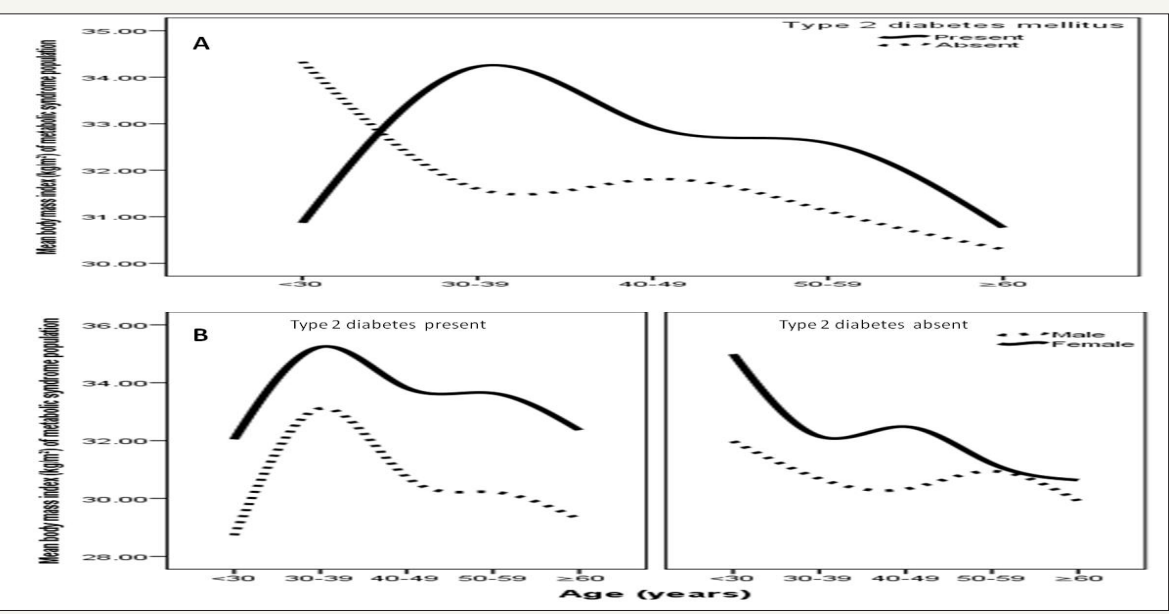

Figure 3: Mean body mass index $\mathrm{kg} / \mathrm{m} 2$ in patients with metabolic syndrome across different age groups stratified to type 2 diabetes (A) and in relation to gender (B). 


\section{Discussion}

The patient populations that we must recognize as being at higher risk of complications from metabolic syndrome or prediabetes include those with known atherosclerosis and vascular disease, a positive family history and genetic background, and phenotypes of insulin resistance (i.e., obesity, polycystic ovary syndrome, women with gestational diabetes, men with androgen deficiency) [16]. Proper definition of the causes and risk factors of MetS is mandatory for prevention or treatment of MetS. In addition to the well-defined risk factors for MetS, there are diseases and conditions that lead to MetS secondarily. Knowing these conditions and defining them as risk factors is of importance in the approach toward patients with MetS. In the present study, in which we aimed to determine prevalence of T2DM that would lead to secondary MetS among Saudi patients, the characteristics of 1967 patients with MetS and/or T2DM were evaluated. Considering the IDF criteria for MetS diagnosis, we showed that around $77.5 \%$ of the cohort analyzed presented the syndrome associated with T2DM, which was nonsignificantly more prevalent in females' individuals (60.2\%, $\mathrm{p}=0.08)$. The current study showed that the prevalence of MetS associated with T2DM was noted to increase from normal weight category [17].

T2DM is a condition conferring insulin resistance presumed to be preceded by MetS. Hyperinsulinemia and insulin resistance are accepted as prominent features of diabetes [18]. Many of the features of MetS, as defined by NCEP ATP III have been shown to be predictors of diabetes, suggesting that, like impaired glucose tolerance and impaired fasting glucose levels, MetS may signal a prediabetic state [19]. Obesity is an alarming public health challenge of the 21st century and an important factor in developing MetS and many chronic diseases, such as CVD, T2DM and HTN [20]. Previous studies have documented an increased risk of mortality due to excess body weight as well as MetS [21,22]. Diabetes appears to be a greater hazard for atherosclerotic cardiovascular disease and stroke than MetS. In the present sample, it is also noteworthy that $77.5 \%$ of MetS patients have T2DM. Thus, although there is a robust relationship between level of obesity and the presence of multiple risk factors, there is considerable variability in the presence of MetS within BMI categories. The idea that some obese individuals appear healthy and display none of the traditional risk factors for chronic disease, including dyslipidemia and insulin resistance, has been reported previously [23]. The prevalence of obesity (BMI $\geq 30 \mathrm{~kg} / \mathrm{m}^{2}$ ) has been steadily increasing, particularly in the younger generation. This may be explained by the fact that fast food restaurants have been quickly gaining popularity in Saudi Arabia, selling unhealthy foods. In addition, market dissemination of the automobile greatly increased during the same period. Studies reported that certain parameters of metabolic status worsen as the severity of obesity increases, whereas others found that the metabolic situation remains the same or even improves with more severe stages of obesity [24]. The reasons for the conflicting results in the various studies are unknown but may occur secondarily to the limited numbers of study subjects in some of these reports.
We found that the pevalence of MetS with T2DM was nonsignificantly higher in females. In Saudi Arabia the prevalence of MetS was found to be $39.8 \%$ (34.4\% in men and 29.2\% in women) and $31.6 \%$ (45.0\% in men and $35.4 \%$ in women), according to the NCEP ATP III and IDF criteria, respectively [25]. Another national study found the prevalence to be $39.3 \%$ in 2005 , using the 2001 ATP III criteria [26]. This indicates that there might be some changes in the risk factors especially among females that can be explained by the fact that females, most of whom are housewives in our society, are more prone to obesity after child birth, besides, women transition from the premenopausal to the postmenopausal stage with substantial metabolic changes and estrogen deficiency might lead to an increased predisposition to metabolic syndrome. The difference in prevalence of MetS between men and women may be related to differences in body fat distribution: men have more visceral and hepatic fat, whereas women have more total body fat [26]. Differences in distribution of fat with age and the cardiometabolic effects of menopause may explain the diminished sex difference in MetS prevalence seen with older age when male predominate [26]. Moreover, in females, menopause and estrogen deficiency appears to be independent predisposing factor for the development of most of the components of the MetS [27].

The age groups $\geq 60$ years had a large prevalence of MetS withT2DM in this study [28]. Also, it is important to note that this middle-aged group (30-39 years and 40-49 years) had a high mean BMI but lower prevalence of overweight or obesity. The other age groups had a lower prevalence of MetS withT2DM than the 30-39 years old, yet it was still relatively high. Whereas it is the elderly who are usually expected to have a higher prevalence of HTN, abnormal cholesterol, or being overweight, because age is a nonmodifiable risk factor for these conditions. It can be explained by the aging process. This is also supported by a study in United Arab Emiates that showed a positive association between the prevalence of metabolic syndrome and age [29]. This observation might be due to a survival effect or participation bias, as individuals prone to obesity-related morbidity and mortality have already died or decline to participate in a study [30]. The observed trend of increasing MetS with T2DM prevalence with age can be explained by the large number of people developing metabolic complications by the time they are aged $\geq 60$ years. Due to the age-related rises of T2DM a more similar make-up of MetS was seen in the elderly, whereas in younger people, the MetS profile was more heterogeneous and differed more by sex. While it may also depend on the definition used for MetS even if the same definition was used, different trends were observed between countries [30]. This underpins the importance of estimating the country-specific prevalence of MetS. One reason for this finding is that the population of Saudi Arabia is changing from its traditional lifestyle to westernized ways and so becoming more subject to similar diseases, the young being more prone in this regard. In contrast, older people, who are less inclined to change their habits, reflected healthier findings. It would be beneficial to identify lifestyle changes among the elderly that could determine the increased tendency to develop risk factors for the diseases of developed countries. It would also be interesting to 
determine to what extent these risk factors are associated with CVD, stroke and/or T2DM among Saudi population, since most studies have been conducted in Caucasian populations.

The clinical utility of MetS in relation to the predictive value of MetS for CVD has been criticized for quit some years [31,32] Criticism is. MetS is found to have no greater predictive value for CVD compared to the individual components [33]. Furthermore, all MetS components are weighted equally while some risk factors are more important for risk prediction. Also, continuous variables are dichotomized and MetS is operationalized as a combination of three or more of the five components, which results in a loss of predictive power [34]. In the current ATPIII definition, only blood pressure and fasting glucose are used for targeted risk factor interventions in clinical practice. Though, interventions are seldom started at the levels proposed by the ATPIII. It is important to observe the prevalence of diabetes, hypertension, and obesity individually and the combination of risk factors as metabolic syndrome to predict the risk of cardiovascular disease. Any association between lifestyle factors and these risk factors would provide the opportunity to encourage a change in lifestyle to promote lower levels of subsequent CVD.

\section{Strengths and limitations}

Our results should be interpreted considering the study's limitations. As this was a hospital-based, retrospective study, the findings do not represent the whole Saudi population or the local community. Further larger population-based studies are necessary to support our findings. Another limitation of the present study was having considered only overall obesity (assessed by BMI) and not abdominal obesity (measured by waist circumference), which is known to bear a close relationship with the target diseases.

\section{Conclusion}

It can be concluded from this study that the prevalence of T2DM among Saudis with MetS is relatively high. Old age and obesity can be regarded as related factors.

\section{Acknowledgment}

We are grateful to the staffs from the Primary care department at King Fahad Armed Forces Hospital for their valuable contributions in data collection. The authors have no conflict of interest to disclose.

\section{References}

1. Pinho PM, Machado LM, Torres RS, Carmin SEM, Mendes WA, et al. (2014) Metabolic syndrome and its relationship with cardiovascular risk scores in adults with non-communicable chronic diseases. Rev Soc Bras Clin Med 12(1): 22-30.

2. Misra A, Khurana L, Isharwal S, Bhardwaj S (2009) South asian diets and insulin resistance. Br J Nutr 101(4): 465-473.

3. Ringborg A, Cropet C, Jönsson B, Gagliardino JJ (2009) Resource use associated with type 2 diabetes in Asia, Latin America, the Middle East and Africa: results from the international diabetes management practices study (IDMPS). International Journal of Clinical Practice 63(7): 997-1007.
4. International Diabetes Federation (2006) The IDF consensus worldwide definition of the metabolic syndrome.

5. Reaven GM (2010) The metabolic syndrome: time to get off the merrygo-round? J Int Med 269: 127-136.

6. Samson SL, Garber AJ (2013) Metabolic syndrome. Endocrinol Metab Clin North Am 43(1): 1-23.

7. Alberti KG, Zimmet PZ (2008) Should we dump the metabolic syndrome? No. BMJ 336(7645): 641.

8. Lorenzo C, Williams K, Hunt KJ (2007) The national cholesterol education program- adult treatment panel iii, international diabetes federation, and world health organization definitions of the metabolic syndrome as predictors of incident cardiovascular disease and diabetes. Diabetes Care 30(1): 8-13.

9. WHO (World Health Organization) (1999) Definition, Diagnosis and Classification of Diabetes Mellitus and its Complications. Report of a WHO Consultation. Part 1: Diagnosis and Classification of Diabetes Mellitus. Department of Non-communicable Disease Surveillance. Geneva, Switzerland.

10. Liu J, Young TK, Zinman B (2006) Lifestyle variables, non-traditional cardiovascular risk factors, and the metabolic syndrome in an Aboriginal Canadian population. Obesity (Silver Spring) 14: 500-508.

11. Green C, Blanchard JF, Young TK (2003) The epidemiology of diabetes in the Manitoba-registered First Nation population: current patterns and comparative trends. Diabetes Care 26(7): 1993-1998.

12. Shaw JE, Sicree RA, Zimmet PZ (2010) Global estimates of the prevalence of diabetes for 2010 and 2030. Diabetes Res Clin Pract 87(1): 4-14.

13. Alberti KG, Zimmet P, Shaw J (2006) Metabolic syndrome a new worldwide definition. A consensus statement from the international diabetes federation. Diabetic Med 23(5): 469-480.

14. American Diabetes Association (2018) Classification and diagnosis of diabetes: standards of medical care in diabetes-2018. Diabetes Care 41(Suppl1): S13-S27.

15. Chen YM, Ho SC, Lam SS, Chan SS (2006) Validity of body mass index and waist circumference in the classification of obesity as compared to percent body fat in Chinese middle-aged women. Int J Obes (Lond) $30(6): 918-925$

16. Kong AP, Luk AO, Chan JC (2016) Detecting people at high risk of type 2 diabetes- how do we find them and who should be treated. Best Pract Res Clin Endocrinol Metab 30(3): 345-355.

17. Ismail MF (2012) Metabolic syndrome among obese qataris attending primary health care centers in Doha, 2010. J Fam Community Med 19(1): 7-11.

18. Hsueh WA (2003) Introduction: new insight into understanding the relation of type 2 diabetes mellitus, insulin resistance, and cardiovascular disease. Am J Cardiol 92 (suppl): 1J-2J.

19. (2001) Expert panel on detection, evaluation, and treatment of high blood cholesterol in adults. executive summary of the third report of the national cholesterol education program (NCEP) expert panel on detection, evaluation and treatment of high blood cholesterol in adults (adult treatment panel iii). JAMA 285(19): 2486-2497.

20. Yeh WT, Chang HY, Yeh CJ, Tsai KS, Chen HJ (2005) Do centrally obese Chinese with normal BMI have increased risk of metabolic disorders? Int J Obes (Lond) 29(7): 818-825.

21. Baik I, Ascherio A, Rimm EB, Giovannucci E, Spiegelman D, et al. (2000) Adiposity and mortality in men. Am J Epidemiol. 152(3): 264-271.

22. Lakka HM, Laaksonen DE, Lakka TA, Niskanen LK, Kumpusalo E, et al. (2002) The metabolic syndrome and total and cardiovascular disease mortality in middle-aged men. JAMA 288(21): 2709-2716. 
23. Karelis AD, St Pierre DH, Conus F, Rabasa Lhoret R, Poehlman ET (2004) Metabolic and body composition factors in subgroups of obesity: what do we know? J Clin Endocrinol Metab 89(6): 2569-2575.

24. Nguyen NT, Magno CP, Lane KT, Hinojosa MW, Lane JS (2008) Association of hypertension, diabetes, dyslipidemia, and metabolic syndrome with obesity: findings from the national health and nutrition examination survey, 1999 to 2004. J Am Coll Surg 207(6): 928-934.

25. Khalid Al R, Nahla B, Yousuf Al Fars, Amira MY, Abdulrahman A, et al. (2018) Prevalence of metabolic syndrome in Saudi Arabia - a cross sectional study. BMC Endocrine Disorders 18: 16.

26. Al Nozha M, Al Khadra, Arafah MR, Al Maatouq, Khalil MZ, et al. (2005) Metabolic syndrome in Saudi Arabia. Saudi Med J 26(12): 1918-1925.

27. Pradhan AD (2014) Sex differences in the metabolic syndrome: implications for cardiovascular health in women. Clin Chem 60(1): 4452 .

28. Carr MC (2003) The emergence of the metabolic syndrome with menopause. J Clin Endocrinol Metab 88(6): 2404-2411.

29. Aguilar M, Bhuket T, Torres S, Liu B, Wong RJ (2015) Prevalence of the metabolic syndrome in the United States, 2003-2012. JAMA 313(19): 1973-1974.
30. Zamboni M, Mazzali G, Zoico E, Harris TB, Meigs JB, et al. (2005) Health consequences of obesity in the elderly: a review of four unresolved questions. Int J Obes (Lond) 29(9): 1011-1029.

31. Kahn R, Buse J, Ferrannini E, Stern M (2005) The metabolic syndrome: time for a critical appraisal. Joint statement from the American Diabetes Association and the European Association for the Study of Diabetes. Diabetologia 48(9): 1684-1699.

32. Reaven GM (2006) The metabolic syndrome: Is this diagnosis necessary? American Journal of Clinical Nutrition 83(6): 1237-1247.

33. Ding EL, Smit LA, Hu FB (2010) The metabolic syndrome as a cluster of risk factors: is the whole greater than the sum of its parts?: Comment on 'The metabolic syndrome, its component risk factors, and progression of coronary atherosclerosis'. Arch Intern Med 170(5): 484-485.

34. Gavrila D, Salmeron D, Egea Caparros JM, Huerta JM, Perez Martinez A, et al. (2011) Prevalence of metabolic syndrome in Murcia Region, a southern European Mediterranean area with low cardiovascular risk and high obesity. BMC Public Health 11: 562.
Creative Commons Attribution 4.0

International License

For possible submissions Click Here
Submit Article

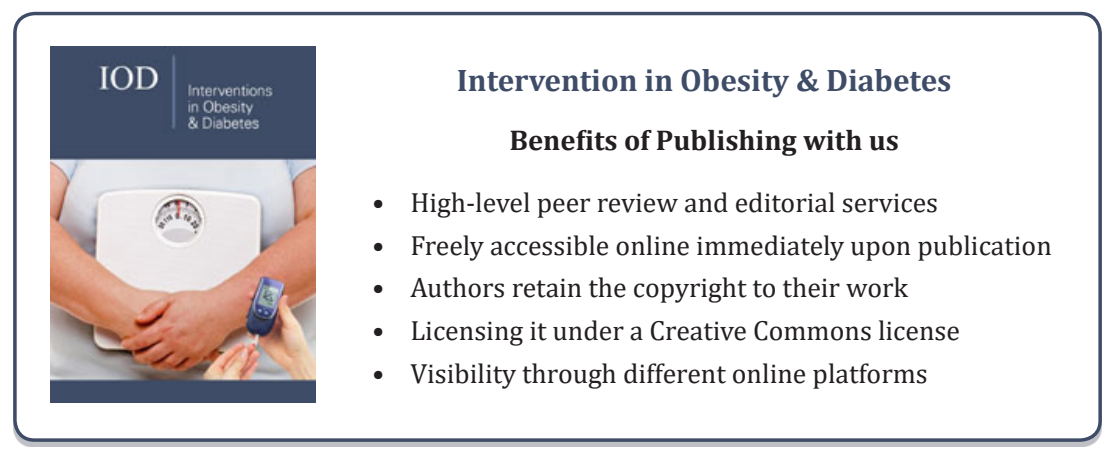

